\title{
Evaluation of Non-proportional Multiaxial Fatigue Strength of Lead-free Solder with Elements Addition
}

\author{
Keiwa Makino ${ }^{1}$, Fumio Ogawa ${ }^{2}$, and Takamoto Itoh $^{2}$ \\ ${ }^{1}$ Graduate School of Science and Engineering, Ritsumeikan University, Japan \\ ${ }^{2}$ College of Science and Engineering, Ritsumeikan University, Japan
}

\begin{abstract}
The effect of element addition on creep and fatigue properties of $\mathrm{Sn1} .0 \mathrm{Ag} 0.7 \mathrm{Cu}$ solder with addition of nickel, germanium and bismuth are reviewed. Element additions imporove creep properties although those deteriorate fatigue properties. From above results, necessity of nonproportional multiaxial fatigue tests are discussed. The load cell with high sensitivity was designed by making to detect small load during fatigue test was developed by making the strain detection part hollow circular. The inner diameter and the outer diameter of the load cell satisfying the condition that excessive strain does not occur regardless of high sensitivity was determined by strength calculation.
\end{abstract}

\section{Introduction}

Recently, solders are utilized in electronic packages to connect electrical components. During use, the temperature of each component changes as the device is switched on and off. Stresses arise in the solder because of the different thermal expansion coefficients of electrical components. Therefore, strength testing of solders under creep and fatigue loading is essential to prevent failure during the operating life of electronic devices.

Currently, lead-free solder is mainly used as a soldering material because lead has negative impact on human body and environment $[1,2]$. SnAgCu (SAC) solder are widely used instead of lead-based solders. However, representative SAC solder $\mathrm{Sn3} .0 \mathrm{Ag} 0.5 \mathrm{Cu}$ (SAC305) is high cost because it contains a large amount of silver. Therefore, it is desirable to use

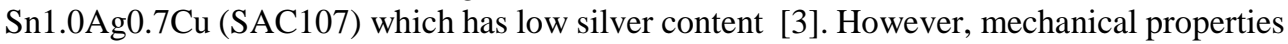
are deteriorated by reduction of silver content. Elements such as nickel, germanium and bismuth are added to improve mechanical properties. However, the effects of element addition on creep and fatigue properties are not fully made clear. In this paper, the recent the authors' results on creep and fatigue properties of SAC107 solder with element addition are reviewed and the importance of investigating non-proportional multiaxial fatigue properties of these solders is discussed.

2 Corresponding author: ogawa-f@fc.ritsumei.ac.jp 


\section{The effect of element addition on creep properties}

\subsection{Microstructure of the solder}

Solders used in this study are based on SAC107. Nickel, germanium and bismuth are added to improve their properties. They are $\mathrm{Sn1} .0 \mathrm{Ag} 0.7 \mathrm{Cu}(\mathrm{SnAgCu}), \mathrm{Sn} 1.0 \mathrm{Ag} 0.7 \mathrm{Cu} 2.0 \mathrm{Bi}$ (SnAgCuBi), Sn1.0Ag0.7Cu0.07Ni0.01Ge (SnAgCuNiGe) and Sn1.0Ag0.7Cu2.0Bi0.07Ni0.01Ge (SnAgCuBiNiGe).

Table 1. Composition of solders.

\begin{tabular}{|c|c|c|c|c|c|c|}
\hline \multirow{2}{*}{ Material } & \multicolumn{7}{|c|}{ Chemical composition (mass \%) } \\
\cline { 2 - 7 } & $\mathrm{Ag}$ & $\mathrm{Cu}$ & $\mathrm{Bi}$ & $\mathrm{Ni}$ & $\mathrm{Ge}$ & $\mathrm{Sn}$ \\
\hline $\mathrm{SnAgCu}$ & 1.0 & 0.7 & - & - & - & Bal. \\
\hline $\mathrm{SnAgCuBi}$ & 1.0 & 0.7 & 2.0 & - & - & Bal. \\
\hline $\mathrm{SnAgCuNiGe}$ & 1.0 & 0.7 & - & 0.07 & 0.01 & Bal. \\
\hline SnAgCuBiNiGe & 1.0 & 0.7 & 2.0 & 0.07 & 0.01 & Bal. \\
\hline
\end{tabular}

Microstructures of the solders were investigated using scanning electron microscopy (SEM) and energy dispersion spectrometry (EDS) mapping. Figure 1 shows observation result of $\mathrm{SnAgCu}[4]$.
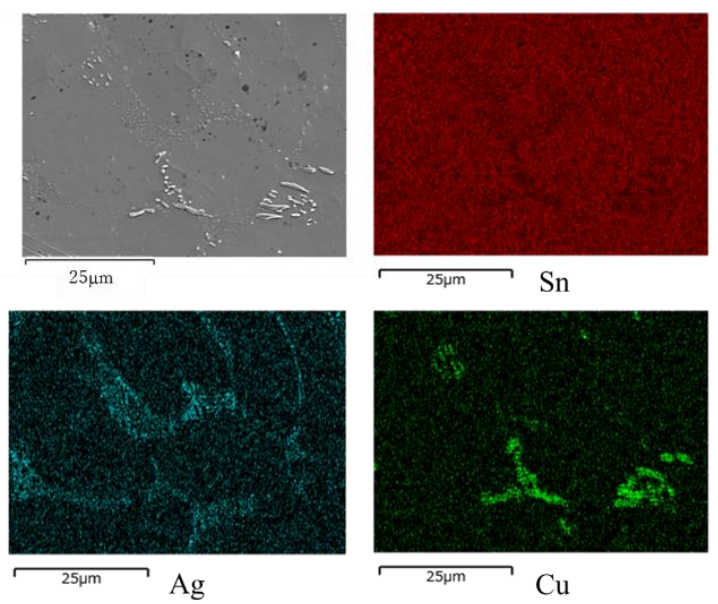

Fig. 1. SEM observation and EDS mapping results for $\mathrm{SnAgCu}$.

The mapping of silver and copper indicates the formation of intermetallics $\mathrm{Ag}_{3} \mathrm{Sn}$ and $\mathrm{Cu}_{6} \mathrm{Sn}_{5}$ at grain boundaries. It is presumed that the intermetallics are beneficial for strengthening of solders.

Figure 2 shows mapping results of tin, silver, copper and bismuth in $\mathrm{SnAgCuBi}$. Intermetallics can be observed as well as $\mathrm{SnAgCu}$ solder. However, it is found that bismuth is homogeneously distributed in the solder. It is suggested that bismuth strengthens mechanical properties through solid solution strengthening. The results of SEM observation and EDS mapping for $\mathrm{SnAgCuNiGe}$ solder indicates that intermetallics $\mathrm{Cu}_{6} \mathrm{Sn}_{5}$ and $\mathrm{Ni}_{6} \mathrm{Sn}_{5}$ are formed (data omitted here). For $\mathrm{SnAgCuBiNiGe}$, the formation of $(\mathrm{Cu}, \mathrm{Ni})_{6} \mathrm{Sn} 5$ [4] was also identified, and homogeneous distribution of bismuth in the solder was confirmed (data omitted here). 

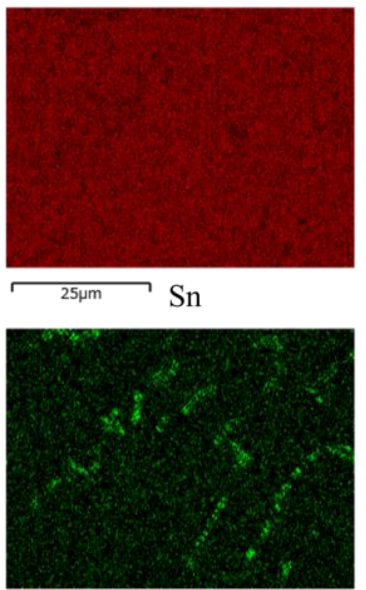

${ }_{25 \mu m} \mathrm{Cu}$
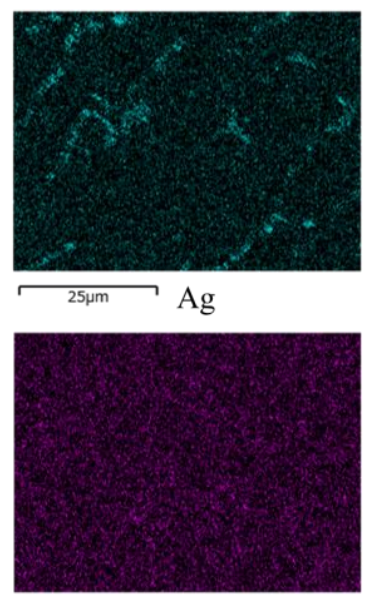

$\mathrm{Bi}$

Fig. 2. EDS mapping results for $\mathrm{SnAgCu}$.

\subsection{Creep properties}

Creep test of solders were performed using miniature creep specimen shown in Figure 3. Creep testing were conducted at $313 \mathrm{~K}, 353 \mathrm{~K}$ and $398 \mathrm{~K}$. Creep strain was recorded and creep rupture lifetime was measured for each solder.

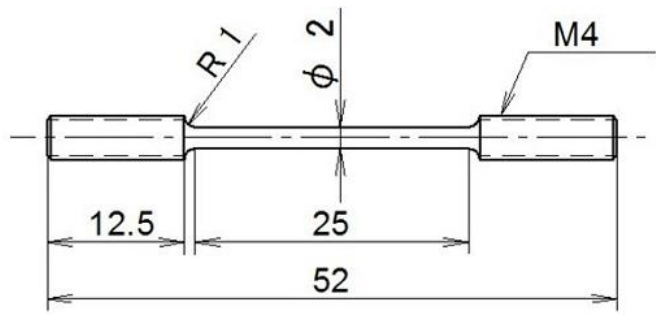

Fig. 3. Shape and dimensions of miniature creep test specimen ( $\mathrm{mm})$.

Figure 4 shows the results of creep tests at $398 \mathrm{~K}$. Creep rupture lifetime was the longest for $\mathrm{SnAgCuBiNiGe}$ solder, and that of $\mathrm{SnAgCuBi}$ was the second longest. Creep properties of solders were improved by element additions. The addition of $\mathrm{Bi}$ is beneficial for the improvement of creep properties.

Figure 5 shows fracture surfaces after creep tests. Figure 5 (a) shows that of $\mathrm{SnAgCu}$, while Figure 5 (b) shows that of $\mathrm{SnAgCuBi}$. A large amount of reduction occurs for $\mathrm{SnAgCu}$, while almost no reduction occurs for $\mathrm{SnAgCuBi}$. The result of interruption tests indicates that coarsening of the intermetallics $\mathrm{Ag}_{3} \mathrm{Sn}$ and $\mathrm{Cu}_{6} \mathrm{Sn}_{5}$ occurred during creep loading (data omitted here). It is estimated that coarsened intermetallics act as crack nucleation sites and deteriorates creep strength of the solders. On the other hand, solid solution strengthening by bismuth leads to high strength, but brittle fracture of the solder takes place. Overall, creep properties of the solders are improved owing to the addition of the elements. 


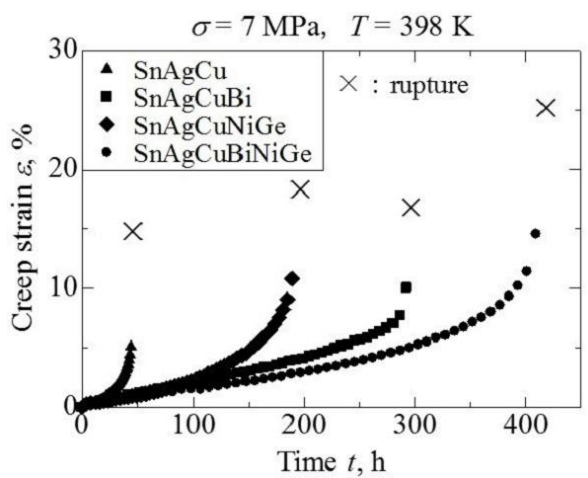

Fig 4. Creep curves of solders at $398 \mathrm{~K}$.
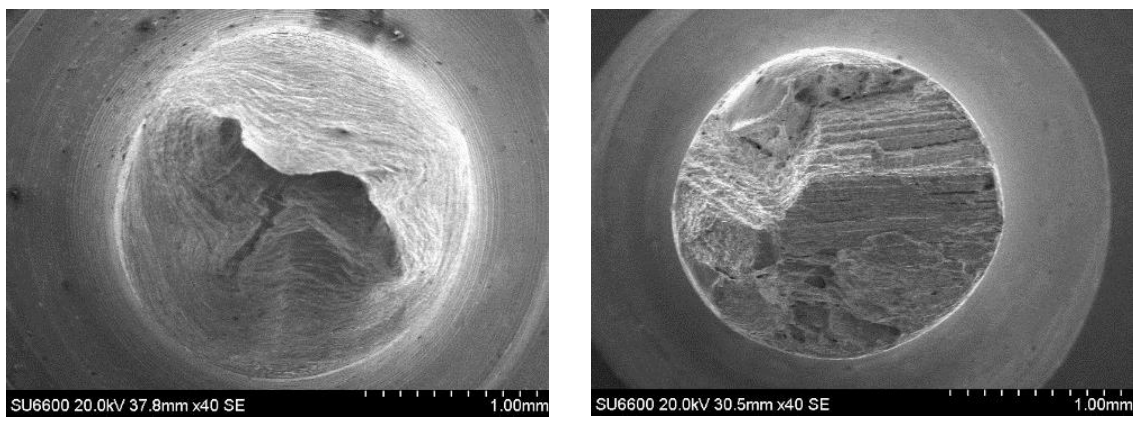

Fig. 5. Fracture surfaces of the solder: (a) $\mathrm{SnAgCu}$, (b) $\mathrm{SnAgCuBi}$.

\section{The effect of element addition on uniaxial fatigue properties}

\subsection{Testing method}

Low-cycle-fatigue tests of solders were performed using a miniature specimen with diameter of $3 \mathrm{~mm}$, gage length of $6 \mathrm{~mm}$, and total length of $55 \mathrm{~mm}$, as shown in Figure 6 . The specimens were made by machining of cast metal. Polishing and heat treatment of the machined specimens were not applied.

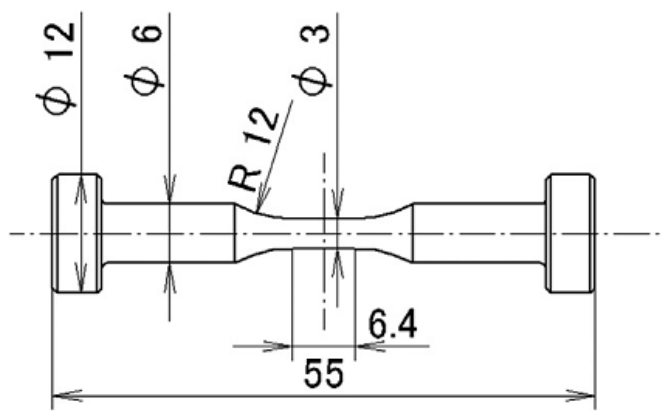

Fig. 6. Shape and dimensions of miniature fatigue test specimen (mm) 
Specimens were heated to a test temperature $40{ }^{\circ} \mathrm{C}$ using an electric furnace. Symmetrical triangular waveform was adopted for low cycle fatigue tests. Strain ranges $(\Delta \varepsilon)$ were $0.5 \%$, $0.7 \%$ and $1.0 \%$ with a strain rate of $0.1 \% / \mathrm{sec}$.

\subsection{Fatigue lives}

Figure 7 shows test results [5]. It is clear that number of cycles to failure are shortened due to element addition. Number of cycles to failure are shorter in the order of $\mathrm{SnAgCuBiNiGe}$, $\mathrm{SnAgCuBi}, \mathrm{SnAgCuNiGe}$ and $\mathrm{SnAgCu}$.

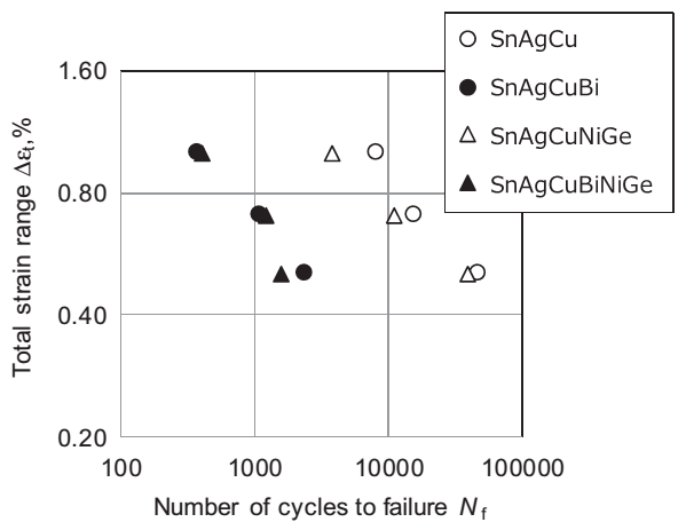

Fig. 7. Relationship between the number of cycles to failure and the total strain range.

For this reason, the following is considered. The solders get harder owing to element addition, leading to high maximum stress during fatigue tests. This phenomenon causes shorter fatigue lives of the solders. Fatigue lives gets shorter in the reversed order to creep rupture lifetime. The element addition has a contradict effect on creep and fatigue properties. Therefore, it should be important to perform creep-fatigue tests to elucidate the effect of element addition on long-term integrity of electronic devices.

Figure 8 illustrate failure process of $\mathrm{SnAgCuNiGe}$ and $\mathrm{SnAgCuBiNiGe}$ during fatigue loading. In $\mathrm{SnAgCuNiGe}$, growth of precipitated phase, i.e. intermetallics occurs and microcracks are formed in the phases. This leads to cyclic softening of the solder during fatigue tests. In the final stage of fatigue tests, microcracks link up to form one macro crack, leading to fatigue failure. On the other hand, no microcracks occurs in the precipitated phases owing to solid solution strengthening by bismuth. The solder is harder compared to other solders and therefore macro cracks propagate from specimen surface.

Element addition alters failure process synergistically with stress during creep and fatigue tests. It is important to consider the effect of combination of stress state and evolution of microstructures during mechanical tests.

\section{Non-proportional multiaxial fatigue tests}

\subsection{Importance of multiaxial fatigue tests}

In the use of practical devices, such as power devices, warp of substrate occurs due to the difference of thermal expansion coefficients of electrical components [6]. This is because electrical current in the devices are quite high compared to ordinary devices. Warp of the 
substrate causes non-proportional multiaxial fatigue loading in the solder. Therefore, it is important to investigate multiaxial fatigue properties. However, there are almost no reports on tension-compression, torsion fatigue tests using small specimens of the solders. Therefore, the authors developed fatigue testing system to perform multiaxial fatigue tests of miniature specimen with gage diameter of $4 \mathrm{~mm}$. A load cell was newly developed to detect small load on solder specimen.

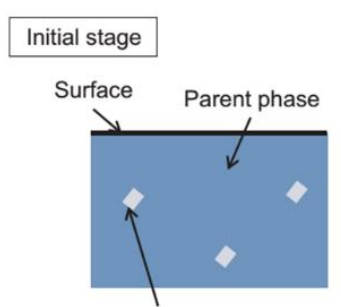

Precipitated phases

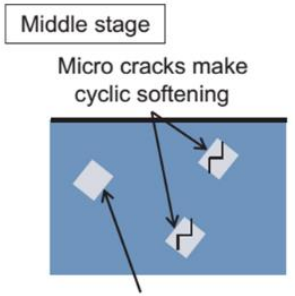

Grown precipitated phases

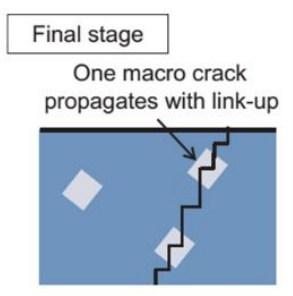

(a) $\mathrm{SnAgCuNiGe}$

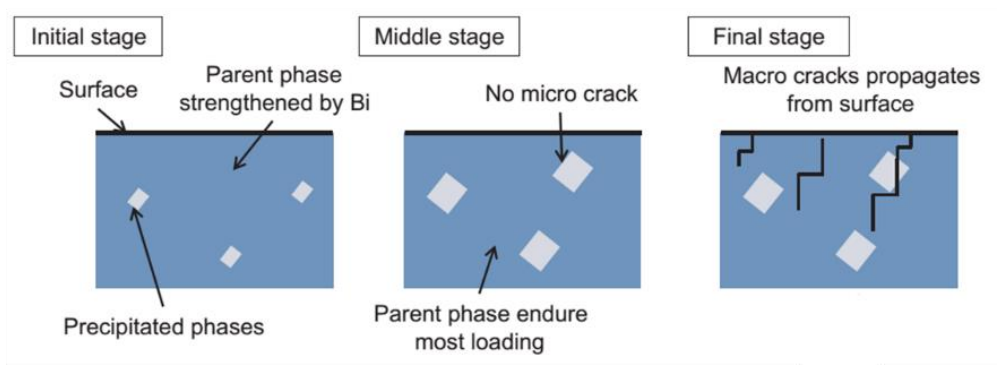

(b) SnAgCuBiNiGe

Fig. 8. Fatigue failure process of solders

(a) $\mathrm{SnAgCuNiGe}$ (b) $\mathrm{SnAgCuBiNiGe}$

\subsection{Development of fatigue testing machine}

Conventional load cell for push-pull test had high strength and could withstand $\pm 5 \mathrm{kN}$, but there was a problem that load resolution was poor and small strain could not be detected. Therefore, a new load cell with high sensitivity was designed by strength calculation. In calculating the strength, the Young's modulus of the load cell $(6061 \mathrm{Al})$ and the solder test piece were set to $68.6 \mathrm{GPa}, 30 \mathrm{GPa}$, respectively. The load applied to the load cell and the test piece was assumed to be equal. Then, the allowable strain of the load cell was set to $0.03 \%$ when the strain generated in the test piece is $1.0 \%$, and the Poisson's ratio is 0.3 . From the above calculation results, the case with an outer diameter of $20 \mathrm{~mm}$ and an inner diameter of $17 \mathrm{~mm}$ was the most appropriate. Figure 9 shows the shape and dimensions of the load cell, and Figure 10 shows a photograph of the load cell. In addition, a cover which can be tightened to the main body by M56 screw was produced.

Two pieces of strain gauges for push-pull loading and torsional loading were attached to the hollow part of the load cell. A two-axis gauge was used as a strain gauge, and a bridge circuit was produced by pasting gages with a 4-gauge method so that strain under nonproportional loading could be detected [7]. 


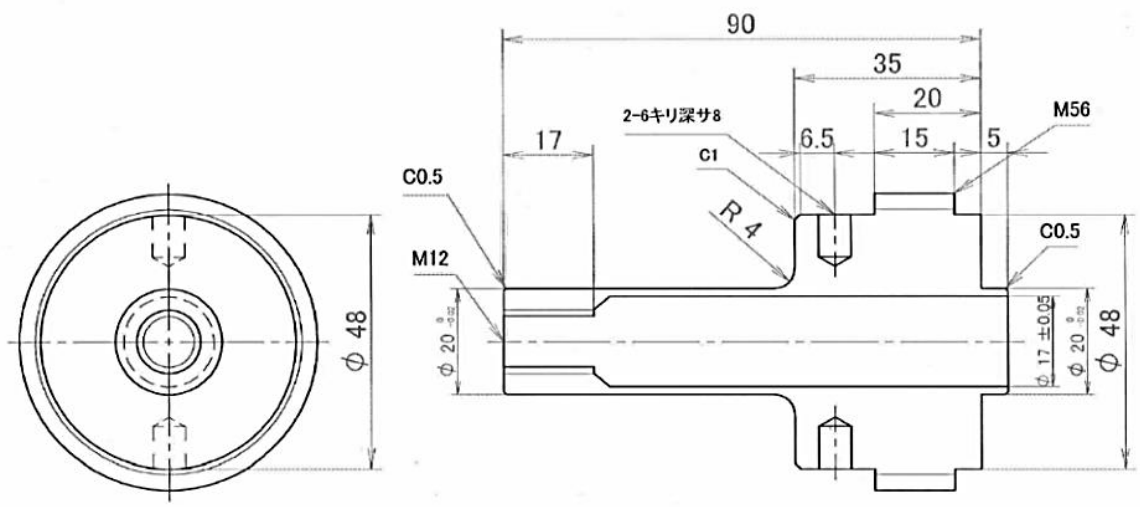

(a) Load cell body
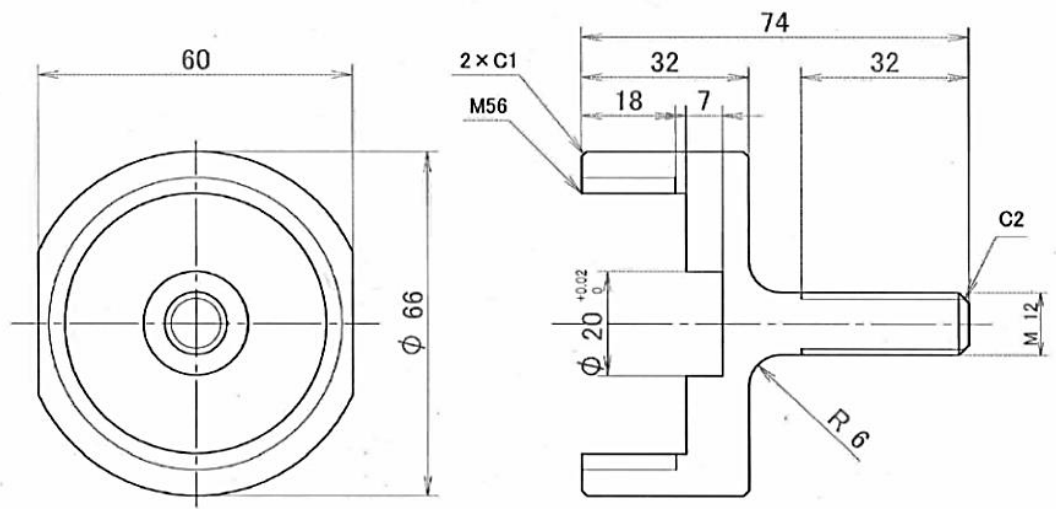

(b) Load cell cover

Fig. 9. Shape and dimensions of the load cell

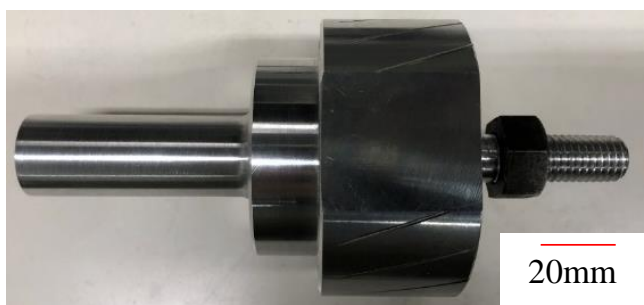

Fig. 10. Photo of the load cell

Figure 11 shows strain paths which will be performed in this study. Reversed-torsion and circle loading in which tension and torsion strains have $90^{\circ}$ phase difference will be performed in addition to push-pull loading. Multiaxial fatigue lives will be compared with those of push-pull and reversed-torsion and the effect of multiaxial loading, i.e. additional hardening by non-proportionality on fatigue lives and failure mechanism will be investigated. Which will be also investigated are the effect of element addition on fatigue lives under circle loading. Cyclic stress-strain relationship will be investigated and failure mechanism will be made clear through observation of fractured specimens. 


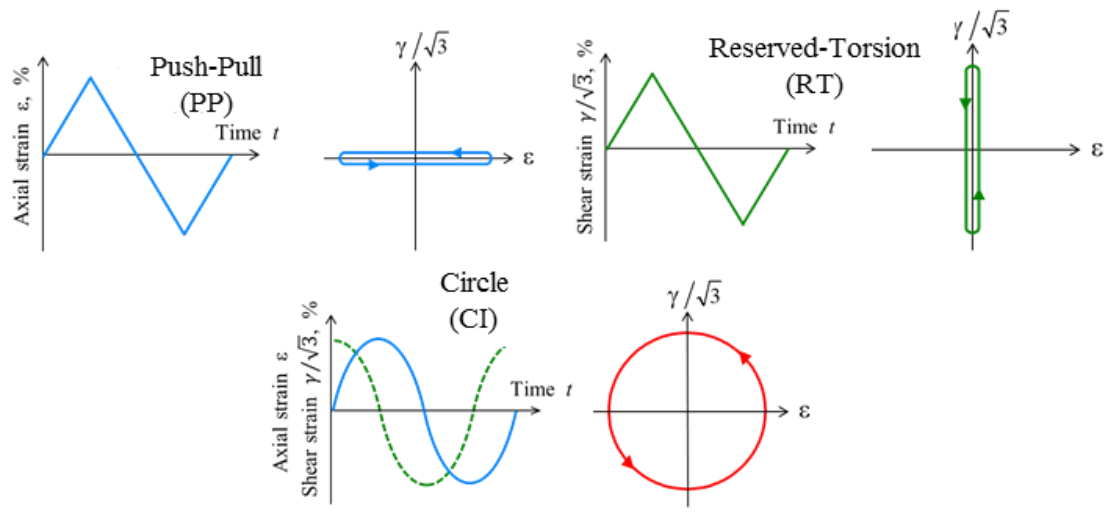

Fig. 11. Strain path of multiaxial fatigue tests

\section{Conclusions}

1. The effect of element additions on creep and fatigue properties of the solders was reviewed and the importance of performing non-proportional multiaxial fatigue tests was discussed.

2. In order to detect small strain during fatigue test under non-proportional loading, a load cell with a hollow circular strain detector was designed. The inner diameter and the outer diameter of the load cell was calculated in order to suppress excessive strain in load cell and to detect small load.

\section{References}

1. M. Abtew, G. Selvaduray, Lead-free Solders in microelectronics, Mater. Sci. Eng. R, 27, 95-141 (2000)

2. J. Glazer, Microstructure and mechanical properties of Pb-free solder alloys for low cost electronic assembly a review, J. Electron. Mater, 23, 693-700 (1994)

3. Y. Hayato, K. Kazama, Mechanical Properties of Low Ag contents Pb-Free Solder Alloys, Proceedings of the 24th Annual Conference of the Electronics Packaging Conference 24, 310-311 (2010)

4. F. Ogawa, H. Nagao, T. Itoh, M. Sakane, M. Yamashita, H. Hokazono, Creep Characteristic of Sn1.0Ag0.7Cu Lead-Free Solders with Element Addition, Applied Mechanics and Materials, 853, 192-196 (2017)

5. H. Kanayama, Y. Konishi, F. Ogawa, T. Itoh, M. Sakane, M. Yamashita, H. Hokazono, Effect of additional elements on the low-cycle-fatigue characteristics of $\mathrm{Sn}-1.0 \mathrm{Ag}-0.7 \mathrm{Cu}$ solder obtained using a miniature-sized specimen, International Journal of Fatigue, 116, 180-191 (2018)

6. M. Mukai, Effect of holding time on thermal fatigue life of solder joints, Proceedings of the Japan Society of Mechanical Engineers A, 1594-1600 (1997)

7. T. Kumagai, Strain gauges and bridge circuits, Measurement and control, 323-328 (2006) 